\title{
Disinfection By-products in Drinking Water
}

Detection and Treatment

2020, Pages 185-204

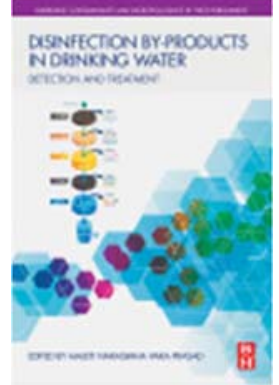

\section{Chapter 8 - Disinfection by-product- induced diseases and human health risk}

Author links open overlay panelEgwariL.O. ${ }^{1}$ BensonN.U. ${ }^{2}$ EffiokW.W. ${ }^{13}$

Department of Biological Sciences, Covenant University, Ota, Nigeria

Department of Chemistry, Covenant University, Ota, Nigeria

National Agency for Food, Drug Administration and Control, Oshodi, Nigeria

Available online 21 February 2020.

Show less

OutlineAdd to Mendeley

Share

Cite

https://doi.org/10.1016/B978-0-08-102977-0.00008-1Get rights and content

\section{Abstract}

This chapter examines the spectrum of health-related diseases associated with exposure to disinfection by-products (DBPs) in disinfected drinking water based on evidences adduced from epidemiological data, experimental animal studies, and other models. Critical evaluation of confounding factors in the design, application, interpretation of results of animal studies, epidemiological 
evidences, corresponding implications in population health impact assessment was presented. The use of predictors or biomarkers in assessing the overall health implications of the complex mixture of DBPs and why only a few DBPs have been regulated despite emerging evidences of more toxic compounds in the DBPs consortium were highlighted. Specific healthassociated references with contacts with trihalomethanes, haloacetic acids, odorous DBPs, 3-chloro-4(dichloromethyl)-5-hydroxy-2(5H) furanone, chlorite, and bromate were discussed. In conclusion the chapter highlighted differences in sourcing and treatment of water by water utilities in developed and developing countries and recommend more elaborate epidemiologicalstudies in defining the actual health implication of exposure to disinfected water.

- Previous chapter

- Next chapter

\section{Keywords}

Health risk

bladder cancer

reproductive health

population health impact assessment

trihalomethanes

haloacetic acids

emerging disinfection by-products

Copyright @ 2020 Elsevier Ltd. All rights reserved.

\section{Recommended articles}

\section{$\bullet$}

Bibliometric review of research trends on disinfection by-products in drinking water during 1975-2018

Separation and Purification Technology, Volume 241, 2020, Article 116741

Download PDFView details

Disinfection by-products in drinking water: detection and treatment methods 
Disinfection By-products in Drinking Water, 2020, pp. 279-304

Download PDFView details

Factors affecting the formation of disinfection by-products in drinking water: human health risk

Disinfection By-products in Drinking Water, 2020, pp. 433-450

Download PDFView details

Citing articles (0) Article Metrics

$12 \mathrm{Next}$

Copyright () 2021 Elsevier B.V. or its licensors or contributors. ScienceDirect ${ }^{\circledR}$ is a registered trademark of Elsevier B.V.

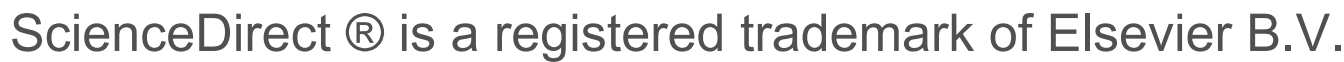

